\title{
Chronic cough in children: bronchoalveolar lavage findings
}

\author{
P.S. Fitch*, ${ }^{*}$, V. Brown ${ }^{+}$, B.C. Schock ${ }^{+}$, R. Taylor ${ }^{\#}$, M. Ennis ${ }^{+}$, M.D. Shields*,\#
}

Chronic cough in children: bronchoalveolar lavage findings. P.S. Fitch, V. Brown, B.C. Schock, R. Taylor, M. Ennis, M.D. Shields. C ERS Journals Ltd 2000.

ABSTRACT: Isolated chronic cough in childhood is a common complaint. Although the symptom cough is included in the definition of childhood asthma, there is debate as to whether the majority of these children have asthma. The authors studied children with isolated chronic cough looking for evidence of airway inflammation typical of asthma, with increased numbers of airway eosinophils as assessed from bronchoalveolar lavage (BAL).

The investigations were carried out on 23 children (median age: 6.7 yrs; (range: 1.7-12.75 yrs), attending the Royal Belfast Hospital for Sick Children for elective surgery, who also had a chronic unexplained cough. Written informed consent was obtained from the parent(s) and a nonbronchoscopic BAL was performed. BAL samples were analysed for total and differential white cell counts and also for the inflammatory mediators, essinophil cationic protein (ECP) and histamine. Results were compared with a group of normal nonatopic children and also a group of atopic asthmatic children, who had been recruited for other studies on airway inflammation.

There was a small but statistically significant increase in BAL percentage eosinophils in the children with chronic cough compared with nonasthmatic controls $(0.28 \%$ versus $0.10 \%, \mathrm{p}=0.03)$. However, the children with cough had lower percentage eosinophils than the atopic asthmatic controls $(0.28 \%$ versus $0.66 \%$, $p=0.01$ ). Three out of 23 children with chronic cough had BAL eosinophils greater than the normal upper $95 \%$ reference interval in BAL. There was a small but statistically significant increase in percentage neutrophils in the children with cough compared with the nonasthmatic controls $(5.85 \%$ versus $3.21 \%, \mathrm{p}=0.03)$. Four out of the 23 children had BAL neutrophils greater than the normal upper $95 \%$ reference interval in BAL.

The authors conclude that only a minority of children with chronic unexplained cough have asthmatic-type airway inflammation. It is speculated that the increased percentage neutrophils in bronchoalveolar lavage from children with cough could relate to underlying persistent airways infection.

Eur Respir J 2000; 16: 1109-1114.
*Depts of Child Health and ${ }^{+}$Clinical

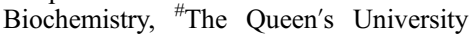
of Belfast and The Royal Belfast Hospital for Sick Children, Belfast.

Correspondence: M.D. Shields

The Dept of Child Health

The Queen's University of Belfast

The Institute of Clinical Science

Grosvenor Road

Belfast BT12 6BJ

Northern Ireland

UK

Fax: 442890236455

Keywords: Asthma

bronchoalveolar lavage

cough

Received: October 201999

Accepted after revision July 102000
Isolated chronic cough in otherwise healthy children is a troublesome symptom that leads to frequent consultations with general practitioners and paediatricians. Prominent causes are: 1) frequently recurring simple viral bronchitis; 2) asthma, sometimes labelled "cough variant asthma"; and 3 ) the postinfectious cough (e.g. following a pertussis-like illness). These common conditions when associated with prolonged periods of coughing but no wheezing can be difficult to clinically differentiate, and there is debate as to how many have cough variant asthma [1-4].

The term cough variant asthma was first applied in 1972 to adults with chronic cough and increased bronchial responsiveness [5]. It was previously thought to be associated with atopy in children, although more recent studies have suggested that atopy is no more common in this group of children than in the general population [6]. In addition, the value of bronchial hyperresponsiveness to diagnose cough variant asthma in children has been questioned, as viral infections may also cause a transient increase in bronchial responsiveness [7]. Some studies have attempted to ascertain the frequency of asthma in this group of children by assessing the response to various trial regimes of antiasthma therapy, usually incorporating inhaled or oral corticosteroids [8-10]. However, in many cases the coughing can be expected to subside with time giving the impression that antiasthma medication has been effective. Some children are unnecessarily exposed to the potential side effects of steroids.

Children with chronic cough, without wheeze, due to cough variant asthma should exhibit airway inflammation similar to known atopic asthmatics, who have increased eosinophils and mast cells in their bronchoalveolar lavage fluid (BAL) [11] and increased concentrations of eosinophil cationic protein (ECP) and histamine in BAL [12]. The aim of the present study was to investigate the cell composition and inflammatory mediators within the airways of children with chronic cough and compare the results with the population of normal nonatopic children and atopic asthmatics, who had undergone lavage for both this and previous studies. 


\section{Methods}

\section{Participants}

Twenty-three children, with a history of isolated chronic cough during the last year, attending the Royal Belfast Hospital for Sick Children for an elective surgical procedure, were recruited with written informed consent from the parents. Since the participants had to be fit for general anaesthesia, they were assessed to be free of current respiratory infection, none had a reported upper respiratory tract infection within the previous 3-4 weeks, and 17 had no reported upper respiratory tract infection for at least 2 months. The children were otherwise well and had a history of chronic cough (lasting at least a month), but no other respiratory symptom including no wheezing. A detailed respiratory and atopy questionnaire was administered to the parents. This included details about the duration of cough, whether it was episodic or persistent in nature, and when the child had last coughed. Children with episodic cough gave a history of prolonged periods of coughing during the previous 12 months, but the parents could also clearly identify asymptomatic interval periods which usually lasted more than 2 weeks. Persistent cough was defined as children who were typically coughing most days or nights of the week and the parents did not identify prolonged asymptomatic interval periods. The authors classified those who had coughed within the last week as "recent", and those who had not coughed in the previous week as "nonrecent". As control groups data on 138 nonatopic controls (79 male, median age 6.7 yrs, range 5 months-14.5 yrs) and 103 atopic asthmatics (67 male, median age 7.4 yrs, range 1.1-15.3 yrs), was available, many of whom were recruited for previous studies [1113]. All surgical procedures were for a noninflammatory condition, the majority being plastic (otoplasty) or opthalmic surgery (squint correction). Atopy was defined as personal atopy (eczema, allergic rhinitis) or a strong family history of atopy (two or more first-degree relatives with atopy) or a raised total serum immunoglobulin (IgE). Ethical approval was given for this study from the Research Ethics committee of the Queen's University of Belfast.

\section{Nonbronchoscopic bronchoalveolar lavage}

This was performed as previously described [13]. Briefly, after induction of anaesthesia an 8 FG neonatal suction catheter was gently inserted down the endotracheal tube until it wedged in a distal bronchus. Sterile normal saline $(20 \mathrm{~mL})$ was injected and immediately aspirated with gentle pulsed suction using the attached syringe.

\section{Cell counts}

Total cell counts were performed using a Neubauer haemocytometer, and differential cell counts performed using a modification of the coverslip method [14] to collect cells on a slide. Cells were stained using the commercially available Diff-Quik $(\mathbb{R}$. A minimum of a 1000 cells was counted for a differential white cell count.
Mast cell counts were assessed using toluidine blue staining, counting 3,000-5,000 cells. The operator was blinded to the clinical category of the sample.

\section{Mediator assays}

Cell free supernatants were obtained by centrifugation $\left(200 \mathrm{~g}, 10 \mathrm{~min}, 4^{\circ} \mathrm{C}\right)$ and stored in aliquots at $-70^{\circ} \mathrm{C}$ until assay. BAL ECP and BAL histamine levels were measured using commercially available immunoassays from Pharmacia Upjohn Ltd (Milton Keynes, UK) and Immunotech (Marseilles, France) respectively. Mediator data are presented as absolute concentrations per $\mathrm{mL}$ of recovered BAL fluid. Total serum IgE was also measured in all patients using a commercially available assay (Pharmacia Upjohn Ltd).

\section{Statistics}

Cell types from the BAL fluid were compared between groups with Kruskal-Wallis and Mann-Whitney tests. Upper limits of normal for each cell type in BAL were taken as the 95th centile in the population of normal nonatopic children, who had undergone BAL for this and previous studies. Comparisons of cellular data between those with and without atopy, those whose cough was persistent or episodic, and between those with recent and nonrecent cough were made.

\section{Results}

Twenty-three children (14 male), median age 6.7 yrs were classified as having chronic isolated cough. Sixteen of these children were classified as being atopic. Seven children were on a $\beta_{2}$-agonist, including one also on inhaled corticosteroids and another also on cromoglycate. The results of the statistical analyses were not altered when the two children receiving anti-inflammatory medication were excluded. Thus data from these children have been included in the reported values. Demographic data including normal controls and asthmatic controls are given in table 1 and data on individual children with chronic cough are given in table 2 .

There was no significant difference in total cell count between children with cough and the population of normal children. Children with chronic cough had significantly higher (median, range) percentage neutrophils in their BAL than the normal controls $(5.9 \%, 1.2-72.7$ versus $3.2 \%, 0.3-83.3, \mathrm{p}=0.03$ ) (fig. 1). They also had a significantly higher percentage eosinophils in BAL $(0.3 \%$,

Table 1. - Demographic data

\begin{tabular}{lccc}
\hline & $\begin{array}{c}\text { Nonatopic } \\
\text { normals }\end{array}$ & $\begin{array}{c}\text { Chronic } \\
\text { cough }\end{array}$ & $\begin{array}{c}\text { Atopic } \\
\text { asthmatics }\end{array}$ \\
\hline Median age (range) & 6.7 & 6.7 & 7.4 \\
& $(0.42-14.5)$ & $(1.7-12.8)$ & $(1.1-15.2)$ \\
Male/Female & $79 / 59$ & $14 / 9$ & $67 / 36$ \\
Passive smoking Y/N & $63 / 64$ & $15 / 8$ & $51 / 44$ \\
Unknown & 11 & 0 & 8 \\
\hline
\end{tabular}

Y: yes; N: No. 
Table 2. - Data on individual children with chronic cough

\begin{tabular}{|c|c|c|c|c|c|c|c|c|}
\hline Patient No & Duration months & Pattern & Recent & Atopy & Recovery \% & Eos \% & Neut $\%$ & Treatment \\
\hline 1 & 5 & $\mathrm{P}$ & $\mathrm{R}$ & $\mathrm{N}$ & 17.5 & 0.00 & 69.8 & $\mathrm{n}$ \\
\hline 2 & 12 & $\mathrm{E}$ & $\mathrm{R}$ & $\mathrm{Y}$ & 42.5 & 0.13 & 8.8 & $\mathrm{n}$ \\
\hline 3 & 12 & $\mathrm{E}$ & NR & $\mathrm{N}$ & 30.0 & 0.00 & 5.8 & $\mathrm{n}$ \\
\hline 4 & 24 & $\mathrm{P}$ & NR & $\mathrm{N}$ & 25.0 & 0.00 & 35.0 & $\mathrm{n}$ \\
\hline 5 & 68 & $\mathrm{E}$ & NR & $\mathrm{N}$ & 35.0 & 0.39 & 2.5 & B2 \\
\hline 6 & 96 & $\mathrm{P}$ & $\mathrm{R}$ & $\mathrm{Y}$ & 20.0 & 0.00 & 7.1 & $\mathrm{ICS}+\mathrm{B} 2$ \\
\hline 7 & 105 & $\mathrm{P}$ & $\mathrm{R}$ & Y & 12.5 & 0.28 & 3.3 & B2 \\
\hline 8 & 54 & $\mathrm{P}$ & NR & $\mathrm{N}$ & 29.0 & 0.85 & 16.5 & B2, DSC \\
\hline 9 & 18 & E & NR & Y & 16.2 & 3.11 & 8.6 & B2 \\
\hline 10 & 18 & E & NR & $\mathrm{N}$ & 41.3 & 0.10 & 72.7 & $\mathrm{n}$ \\
\hline 11 & 14 & $\mathrm{P}$ & $\mathrm{R}$ & $\mathrm{Y}$ & 22.5 & 0.00 & 12.0 & $\mathrm{n}$ \\
\hline 12 & 3 & $\mathrm{E}$ & $\mathrm{R}$ & $\mathrm{Y}$ & 42.5 & 0.00 & 2.0 & $\mathrm{n}$ \\
\hline 13 & 60 & $\mathrm{E}$ & NR & $\mathrm{Y}$ & 42.5 & 0.84 & 1.4 & $\mathrm{n}$ \\
\hline 14 & 9 & $\mathrm{E}$ & NR & $\mathrm{Y}$ & 33.3 & 0.28 & 11.1 & $\mathrm{n}$ \\
\hline 15 & 9 & $\mathrm{E}$ & NR & $\mathrm{Y}$ & 35.0 & 0.85 & 4.0 & $\mathrm{n}$ \\
\hline 16 & 6 & E & NR & Y & 60.0 & 0.25 & 1.3 & $\mathrm{n}$ \\
\hline 17 & 12 & $\mathrm{P}$ & $\mathrm{R}$ & Y & 28.0 & 0.19 & 1.2 & B2 \\
\hline 18 & 96 & $\mathrm{P}$ & $\mathrm{R}$ & $\mathrm{Y}$ & 42.5 & 0.56 & 64.9 & $\mathrm{n}$ \\
\hline 19 & 52 & $\mathrm{P}$ & $\mathrm{R}$ & $\mathrm{Y}$ & 35.0 & 3.75 & 5.4 & B2 \\
\hline 20 & 34 & $\mathrm{P}$ & $\mathrm{R}$ & $\mathrm{Y}$ & 20.0 & 4.79 & 10.4 & $\mathrm{n}$ \\
\hline 21 & unknown & E & NR & Y & 55.0 & 0.48 & 1.6 & $\mathrm{n}$ \\
\hline 22 & 4 & $\mathrm{P}$ & $\mathrm{R}$ & $\mathrm{N}$ & 37.5 & 0.29 & 5.2 & $\mathrm{n}$ \\
\hline 23 & 4 & $\mathrm{P}$ & $\mathrm{R}$ & $\mathrm{Y}$ & 35.0 & 0.00 & 1.2 & $\mathrm{n}$ \\
\hline
\end{tabular}

E: episodic cough; P: persistent cough; R: recent symptoms; NR: nonrecent symptoms; Y: atopy present; N: atopy absent; Recovery \%: percentage recovery of the infused lavage fluid; Eos \%: per cent eosinophils in bronchoalveolar lavage fluid: Neut \%: per cent neutrophils in bronchoalveolar lavage fluid; n: no treatment; B2: $\beta_{2}$ agonist; ICS: inhaled corticosteroids; DSC: disodium cromoglycate.

0.0-4.8 versus $0.1 \%, 0.0-4.1, \mathrm{p}=0.03$ ) (fig. 2) and significantly lower percentage epithelial cells $(0.9 \%, 0.0$ 60.7 versus $9.1 \%, 0.0-71.8, \mathrm{p}=0.02)$. All other cell types showed no significant difference compared to normal controls. The percentage eosinophils was significantly higher in the asthmatic group $(0.7 \%, 0.0-26.2$ versus 0.3 , $0.0-4.8, \mathrm{p}=0.012$ ) compared with the chronic cough group (fig. 2). Percentage neutrophils in atopic asthmatics, however, was similar to the levels in normals and lower than in children with cough, although this did not quite reach statistical significance $(3.3 \%, 0.2-96.4$ versus $5.9 \%, 1.2-72.7, \mathrm{p}=0.055)$. Dividing the cough group into

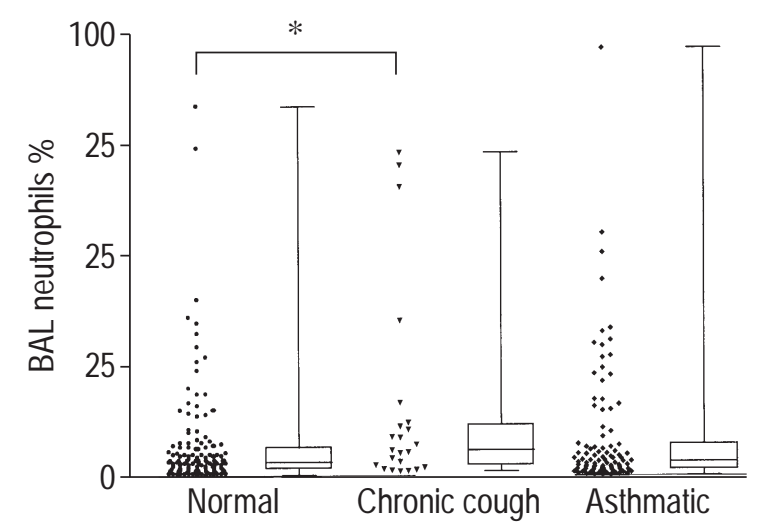

Fig. 1. - Percentage neutrophils in bronchoalveolar lavage fluid in normal nonatopic children $(n=138)$, children with chronic cough $(n=23)$ and atopic asthmatics $(n=103)$. Data are given as single points and as box and whisker plots, whereby the box extends from the 25 th percentile to the 75th percentile with a horizontal line at the median (50th percentile) and the whiskers extend down to the smallest value and up to the largest. Statistical analysis was performed using Mann-Whitney Utest. $*: \mathrm{p}=0.03$. atopic $(n=16)$ and nonatopic $(n=7)$ did not reveal any significant differences in the percentage eosinophils $(0.3 \%, 0.0-4.8$ versus $0.1 \%, 0.0-0.9, \mathrm{p}=0.29)$, whereas there was a trend towards higher percentage neutrophils in the nonatopic group $(16.5 \%, 2.5-72.7$ versus $4.7 \%$, $1.2-64.9, \mathrm{p}=0.053)$.

Children with cough were divided into those with an episodic pattern of cough $(n=11)$ and those whose cough was persistent $(\mathrm{n}=12)$ (table 2$)$. However, there was no

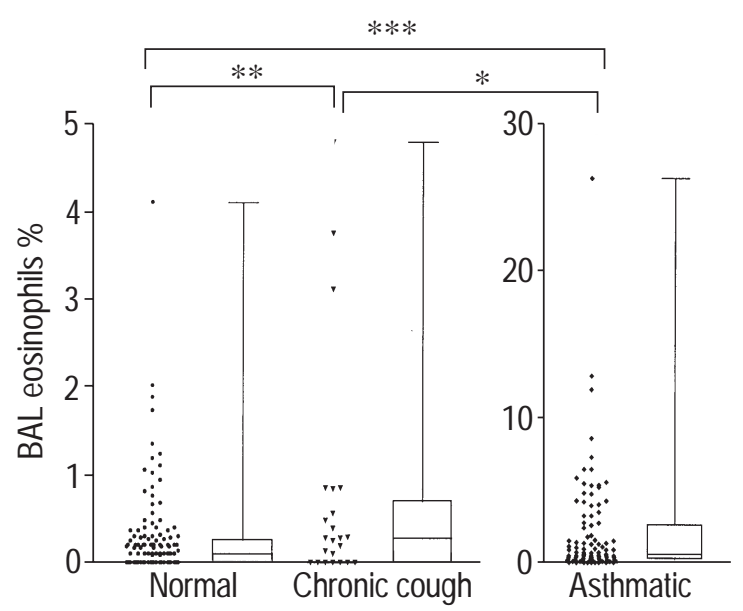

Fig. 2. - Percentage eosinophils in bronchoalveolar lavage fluid in normal nonatopic children $(n=138)$, children with chronic cough $(n=23)$ and atopic asthmatics $(n=103)$. Data are given as single points and as box and whisker plots, whereby the box extends from the 25 th percentile to the 75th percentile, with a horizontal line at the median (50th percentile) and the whiskers extend down to the smallest value and up to the largest. Statistical analysis was performed using Mann-Whitney Utest. *: $\mathrm{p}=0.01 ; * *: \mathrm{p}=0.03 ; * * *: \mathrm{p}<0.001$. 
significant difference in percentage neutrophils in the children with persistent cough versus children with episodic cough $(8.8 \%, 1.2-69.8$ versus $4.0 \%, 1.3-72.7$, $\mathrm{p}=0.3$ ). There was also no significant difference in percentage eosinophils between these subgroups $(0.23 \%$, $0.00-4.79$ versus $0.28 \%, 0.00-3.11, \mathrm{p}=0.7$, respectively). Children whose cough had occurred within the last week (recent, $n=13$ ), were also compared with those who had not coughed for at least a week (nonrecent, $n=10)$ (table 2). Again there was no significant difference between those children with recent symptoms and those with nonrecent symptoms with respect to neutrophils $(6.3 \%$, $1.2-69.8$ versus $5.8 \%, 1.3-72.7, \mathrm{p}=0.95)$ and eosinophils $(0.2 \%, 0.0-4.8$ versus $0.4 \%, 0.0-3.1, \mathrm{p}=0.3)$. However, two children with a typical persistent pattern of symptoms had no symptoms in the past week and were therefore, classified as nonrecent.

ECP was detectable in BAL fluid in 3 out of $22(14 \%)$ children with chronic unexplained cough compared with 6 out of $81(7 \%)$ normal children and 27 out 97 (28\%) atopic asthmatic children. BAL histamine was not significantly increased in the chronic cough group compared with the normal children (4.7 nM, 0.2-225.8 versus $2.6 \mathrm{nM}, 0.1-$ 103.7, $\mathrm{p}=0.68$ ) (fig. 3). Although BAL histamine was significantly higher in the atopic asthmatics $(7.0 \mathrm{nM}, 0.2-$ 686.7) compared with the normal children $(p=0.002)$, there was no significant difference in BAL histamine between the atopic asthmatics and the children with cough (fig. 3).

A greater proportion of children with chronic cough were exposed to environmental cigarette smoke compared with the control children, however, this did not reach statistical significance $(\mathrm{p}=0.18$, Fisher's exact test, odds ratio (OR) 1.9, 95\% confidence interval (CI) 0.8-4.8). In addition, amongst the children with cough there was no significant difference in BAL percentage neutrophils between the passive smokers and the nonpassive smokers (5.4\%, 1.7-69.8 versus $8.1 \%, 1.3-72.7, \mathrm{p}=0.443)$.

The number of children with chronic cough who had elevated BAL eosinophils and also the number who had

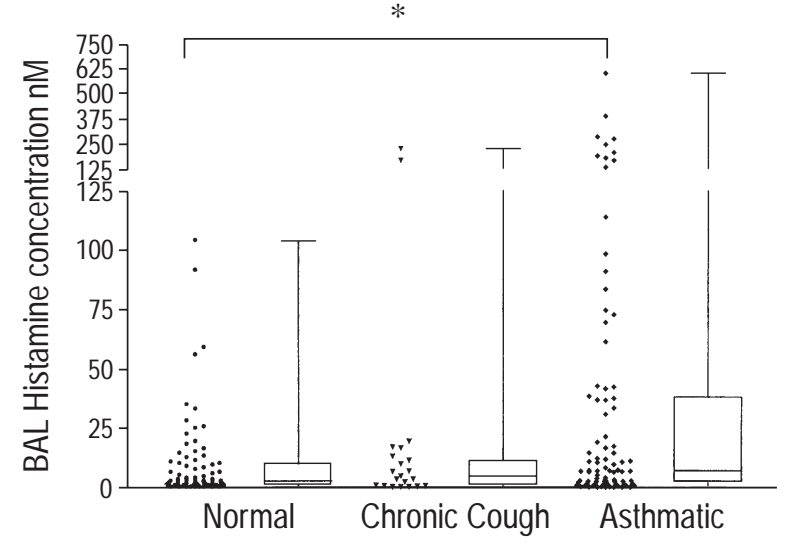

Fig. 3. - Histamine concentration in bronchoalveolar lavage fluid in normal nonatopic children $(n=88)$, children with chronic cough $(n=21)$ and atopic asthmatics $(\mathrm{n}=77)$. Data are given as single points and as box and whisker plots, whereby the box extends from the 25 th percentile to the 75 th percentile, with horizontal line at the median (50th percentile) and the whiskers extend down to the smallest value and up to the largest. Statistical analysis was performed using Mann-Whitney U-test. *: $\mathrm{p}=0.002$. elevated BAL neutrophils were examined. To do this the authors used the upper 95th centile from the population of normal nonatopic children for BAL percentage of eosinophils and neutrophils to divide the group according to whether there was eosinophilic airway inflammation or neutrophilic inflammation. Three patients had eosinophilic airway inflammation (defined as eosinophils $\geq 1.19 \%$ ). Another four patients had neutrophilic airway inflammation (defined as neutrophils $\geq 24.41 \%$ ). By far the majority (16 participants) had evidence of neither eosinophilic or neutrophilic airway inflammation.

\section{Discussion}

In the study the inflammatory cell profile and mediator content in BAL in 23 children with isolated chronic cough with both normal control children and atopic asthmatic children were compared. A small but statistically significant increase in eosinophil and neutrophil percentages in the BAL fluid of children with isolated chronic cough compared to normal were found. However, only three of the 23 children with coughing had elevated BAL eosinophil percentages above normal. This suggests that only a minority of these children have asthmatic type airways inflammation with elevated eosinophils. The authors believe that these children are representative of the type of child that might be taken to see a general practitioner with a "problem cough". However, as only seven out of 23 patients were on treatment it is likely that these children had the milder end of the spectrum of chronic cough.

The percentage eosinophils in BAL samples from children with cough were slightly but significantly raised compared to normal nonatopic children. However, there was a much greater increase in eosinophil percentages in the atopic asthmatic group. Thus the cough group is intermediate between normal control children and atopic asthmatics in terms of airway inflammation. MARGUET et al. [15] found no difference between the cough and control groups; thus the present results are not entirely consistent with their findings. Biopsies from seven children with unexplained cough revealed mucosal oedema and an inflammatory cell infiltrate consisting mainly of Iymphocytes [16]. In three out of 23 children BAL percentage eosinophils were elevated. Using this as the gold standard for diagnosing asthma, then these children should be diagnosed as asthmatic. In addition a fourth patient, on regular inhaled corticosteroids for cough, might have had suppression of BAL eosinophil numbers. BAL histamine concentrations did not differ between control children and the children with cough, although they were raised in atopic asthmatics compared with control children. Thus as a group, children with cough tend not to have asthmatype airway inflammation.

It is important to try to identify which factors are associated with airway inflammation in children with cough. Atopy did not predict eosinophilic airway inflammation, since median percentage eosinophils were no higher in the atopic children with cough than the nonatopic children with cough. There was also no significant difference in mast cells, histamine or ECP between these subgroups. In addition, the clinical features of the cough were examined, namely whether it was episodic or persistent and also how recent the last episode of coughing 
occurred. Again there was no significant difference between subgroups. However, the numbers may have been too small to reveal a significant difference. Alternatively a true difference may have been obscured if the parental history was inaccurate. Furthermore, BAL samples which are only a small segment of the total airway and at a single time-point make it possible that airway inflammation may exist only in the mucosa and submucosa and not be found in the airway lumen, although this is unlikely.

The cough group had a significantly higher percentage of BAL neutrophils compared with the control children. However, only a minority of the group had true neutrophilic inflammation. These children may have recurrent viral infection as the underlying cause of cough since viral infections are known to induce neutrophilia e.g. in bronchial lavage and nasopharyngeal secretions from infants with respiratory syncytial virus infection [17]. Both healthy and asthmatic subjects have significantly increased induced sputum neutrophils during experimental rhinovirus-16 infection [18].

A higher percentage of neutrophils in the children with cough may also be explained by exposure to environmental tobacco smoke, as smoking in adults is known to increase neutrophil numbers in BAL [19]. In support of this, it was found that the OR for a child with cough being exposed to environmental tobacco smoke, compared to a child without cough, was 1.9. This did not reach statistical significance, presumably because of the small numbers in the cough group. However, this finding is not unexpected because a large epidemiological survey in children found that the only independent risk factor for recurrent cough without wheeze was a history of parental smoking [6]. The data do not support the theory that exposure to environmental tobacco smoke causes neutrophilic airway inflammation, as the percentage BAL neutrophils did not differ between children exposed or not exposed to cigarette smoke.

Several studies have looked at airway inflammation in adults with isolated chronic cough. The majority of studies in adults suggest that eosinophilic airway inflammation is a feature of chronic cough. FuJIMURA et al. [20] found high rates of sputum eosinophilia suggesting that their group of adults with chronic cough may have been asthmatic [20]. NiImi et al. [21] found that percentages of eosinophils and ECP in the cough group were similar to that of confirmed asthmatics and significantly higher than controls. McGarveY et al. [22] using a comprehensive diagnostic protocol for chronic nonproductive cough in adults, divided patients according to aetiology of cough. They found that both asthmatic cough and nonasthmatic cough were associated with increased numbers of eosinophils in BAL and that in the cough group as a whole there was an increased concentration of histamine compared with controls [23].

A deficiency of this study and also with many paediatric studies on cough is the inaccuracy of parental cough reporting, which is manifest by poor reproducibility in cough reporting on separate occasions [24]. PicciotTo et al. [25] attempted to overcome this when examining nocturnal cough in children by the use of videorecording in the children homes. For ethical reasons, the authors were unable to investigate these children further to exclude alternative diagnoses as these children were attending hospital not for cough but for elective surgery.
The children that were studied had mild symptoms and no other symptoms suggestive of alternative diagnoses.

It seems likely that the patients with chronic cough and evidence of eosinophilic airway inflammation are those most likely to respond to antiasthma therapy, although this remains to be proven. A noninvasive and specific marker of eosinophilic airway inflammation would be a valuable tool to study this, and exhaled nitric oxide may be useful in this regard. Others have tried to distinguish different causes of chronic cough using some feature of the bronchial responsiveness plot [8] or cough receptor sensitivity to capsaicin in children [26]. However, both of these techniques appear to have little value in distinguishing which children with chronic cough will respond to antiasthma therapy.

It is concluded that chronic unexplained cough in children with no other symptoms represents a heterogeneous group with different underlying causes. However, from the data presented the authors believe that only a minority of these children have true cough variant asthma with eosinophilic airways inflammation.

\footnotetext{
Acknowledgements. The authors gratefully acknowledge the support of the National Asthma Campaign.
}

\section{References}

1. Spelman R. Two-year follow up of the management of chronic or recurrent cough in children according to an asthma protocol. Br J Gen Pract 1991; 41: 406-409.

2. Parks DP, Ahrens RC, Humphries CT, Weinberger MM. Chronic cough in childhood: approach to diagnosis and treatment. J Pediatr 1989; 115: 856-862.

3. Mckenzie S. Cough - but is it asthma? Arch Dis Child 1994; 70: 1-2.

4. Faniran AO, Peat JK, Woolcock AJ. Persistent cough: is it asthma? Arch Dis Child 1998; 79: 411-414.

5. Glauser GL. Variant asthma. Ann Allergy 1972; 30(8): 457-459.

6. Wright AL, Holberg CJ, Morgan WJ, Taussig LM, Halonen M, Martinez FD. Recurrent cough in childhood and its relation to asthma. Am J Respir Crit Care Med 1996; 153: 1259-1265.

7. Brooke AM, Lambert PC, Burton PR, Clarke C, Luyt DK, Simpson H. Recurrent cough: natural history and significance in early childhood. Pediatr Pulmonol 1998; 26: 256-261.

8. Irwin RS, French CT, Smyrnios NA, Curley FJ. Interpretation of positive results of a methacholine inhalation challenge and 1 week of inhaled bronchodilator use in diagnosing cough-variant asthma. Arch Intern Med 1997; 157: 1981-1987.

9. Cheriyan S, Greenberger P, Patterson R. Outcome of cough variant asthma treated with inhaled steroids. Ann Allergy 1994; 73(6): 478-480.

10. Millar MM, McGrath KG, Patterson R. Malignant cough equivalent asthma: definition and case reports. Ann Allergy Asthma Immunol 1998; 80: 345-351.

11. Stevenson EC, Turner G, Heaney LG, et al. Bronchoalveolar lavage findings suggest two different forms of 
childhood asthma. Clin Exp Allergy 1997; 27: 10271035.

12. Ennis M, Turner G, Schock BC, et al. Inflammatory mediators in bronchoalveolar lavage samples from children with and without asthma. Clin Exp Allergy 1999; 29: 362-366.

13. Heaney LG, Stevenson EC, Turner G, et al. Investigating paediatric airways by non-bronchoscopic lavage: normal cellular data. Clin Exp Allergy 1996; 26: 799-806.

14. Laviolette M, Carreau M, Coulombe R. Bronchoalveolar lavage cell differential on microscope glass cover. Am Rev Resp Dis 1988; 138: 451-457.

15. Marguet C, Jouen-Boedes F, Dean TP, Warner JO. Bronchoalveolar cell profiles in children with asthma, infantile wheeze, chronic cough or cystic fibrosis. $A m J$ Respir Crit Care Med 1999; 159: 1533-1540.

16. Heino M, Juntunen-Backman K, Leijala M, Rapola J, Laitinen LA. Bronchial epithelial inflammation in children with chronic cough after early lower respiratory tract illness. Am Rev Resp Dis 1990; 141: 428-432.

17. Everard ML, Swarbrick A, Wrightham M, et al. Analysis of cells obtained by bronchial lavage of infants with respiratory syncytial virus infection. Arch Dis Child 1994; 71: 428-432.

18. Fleming HE, Little FF, Schnurr D, et al. Rhinovirus-16 colds in healthy and asthmatic subjects - similar changes in upper and lower airways. Am J Respir Crit Care Med 1999; 160: 100-108.
19. The BAL Cooperative Group Steering Committee. Bronchoalveolar lavage constituents in healthy individuals, idiopathic pulmonary fibrosis, and selected comparison groups. Am Rev Respir Dis 1990; 141: S169-S202.

20. Fujimura M, Songur N, Kamio Y, Matsuda T. Detection of eosinophils in hypertonic saline induced sputum in patients with chronic non productive cough. J Asthma 1997; 34: 119-126.

21. Niimi A, Amitani R, Suzuki K, Tanaka E, Murayama T, Kuze F. Eosinophilic inflammation in cough variant asthma. Eur Respir J 1998; 11: 1064-1069.

22. McGarvey LPA, Heaney LG, Lawson JT, et al. Evaluation and outcome of patients with chronic nonproductive cough using a comprehensive diagnostic protocol. Thorax 1998; 53: 738-743.

23. McGarvey LPA, Forsythe P, Heaney LG, MacMahon J, Ennis M. Bronchoalveolar lavage findings in patients with chronic nonproductive cough. Eur Respir J 1999; 13: $59-65$.

24. Chang AB. Cough, cough receptors and asthma in children. Pediatr Pulmonol 1999; 28: 59-70.

25. Picciotto A, Fuller P, Hubbard M, McKenzie SA. Videorecording at night in childrens homes. Int $J$ Soc Res 1998; 1: 153-161.

26. Chang AB, Phelan PD, Sawyer SM, Robertson CF. Airway hyperresponsiveness and cough-receptor sensitivity in children with recurrent cough. Am J Respir Crit Care Med 1997; 155: 1935-1939. 